\title{
LA PEDAGOGÍA SOCIAL: UNA DISCIPLINA BÁSICA EN LA SOCIEDAD ACTUAL
}

\author{
M. R. L. MENDIZABAL
}

Universidad Complutense de Madrid mrlimonm@edu.ucm.es

Artículo presentado en junio/2016 y aceptado en julio/2016

DOI: $10.15628 /$ holos.2016.4729

\section{RESUMEN}

La Pedagogía Social es una importante área de especialización educativa en las Universidades Europeas

compleja y poliédrica. El artículo describe las etapas de su y de creciente implantación y desarrollo en las Universidades Latinoamericanas y también es un campo de actividad profesional de los educadores y pedagogos sociales, necesario en la sociedad actual, demasiado desarrollo como disciplina científica así como las diversas concepciones de esta, con especial referencia al pensamiento del profesorado universitario de Pedagogía Social de la Universidad Complutense de Madrid.

PALABRAS CLAVE: Pedagogía Social; Educación Social; Educación Permanente; Universidad; Educador Social.

\section{O ENSINO SOCIAL: UMA DISCIPLINA FUNDAMENTAL NA SOCIEDADE DE HOJE}

\section{RESUMO}

Pedagogia Social é uma importante área de especialização educacional nas universidades europeias e criação cada vez mais e desenvolvimento em universidades da América Latina e é também um campo de actividade profissional dos educadores e pedagogos sociais, necessárias na sociedade de hoje, muito

complexo e multifacetado. $\mathrm{O}$ artigo descreve os estágios de seu desenvolvimento como disciplina científica e as diversas concepções de este, com especial referência ao pensamento do corpo docente da Universidade de Pedagogia Social da Universidade Complutense de Madrid.

PALAVRAS-CHAVE: Pedagogia social; Educação social; Educação Continuada; Universidade; Educador social. 


\section{LOS ORÍGENES DE LA PEDAGOGÍA SOCIAL CONTEMPORÁNEA}

Desde que Diesterweg en 1850 introduce el término Pedagogía Social - Sozialpädagogik"hasta nuestros días, la Pedagogía Social ha pasado por diferentes etapas o fases de construcción y consolidación. Por ello, podemos afirmar que es una ciencia relativamente joven.

No queremos con ello significar que anteriormente no existiese una preocupación por la educación social, ya que como señala el profesor Quintana (1984, p.11) "se ha teorizado sobre educación social y sobre funciones sociales de la educación desde siempre", y esto podemos constatarlo desde Platón a Pestalozzi, pasando por otros autores como Aristóteles, Ramón Llull, Juan Luis Vives, Comenio, Montesquieu, Basedow, Salzmann, etc.; en todos ellos se pone de relieve el interés por las cuestiones educativas en el ámbito social.

Diversos autores como Luzuriaga (1968, p.14), Negrín (1977, p.10) señalan que sería posible establecer una separación entre los denominados "precursores o antecesores" en la pedagogía clásica (desde Platón a Pestalozzi) y sus "fundadores o creadores teóricos" (desde Natorp hasta la actualidad). Dichos precursores o antecesores no suponen lógicamente una etapa en sí misma constitutiva del cuerpo científico como tal de la Pedagogía Social, sino que contienen multitud de heterogéneas aportaciones que han servido de base para el desarrollo de la humanidad y de la educación.

Consideramos que independientemente de que sea factible apreciar en el pensamiento antiguo y en etapas posteriores, algunos indicios de lo que hoy denominamos Pedagogía Social, resulta obvio que las primeras especulaciones sistematizadas sobre su cuestión se registran a partir de finales del siglo XIX.

Los orígenes de la Pedagogía Social van asociados a la sociedad industrial y a las profundas alteraciones que se producen ante los fenómenos de masificación urbana, proletarización del campesinado, relajación de vínculos familiares, desigualdades sociales, pobreza; Radl (1984, p.28) señala que "verdaderamente se entiende el origen de la Pedagogía Social a través de los cambios esenciales en la sociedad tradicional-absolutista hacia una sociedad industrial capitalista".

"Nace el término como un referente de problemas asociados al nacimiento de la revolución industrial para los cuales se intentaba buscar una respuesta pedagógica y con nuevas formas de actuación y organismos sociales adecuados" (Arroyo, 1985, p.206).

Mollenhauer (1959) señala en su monografía (en la que estudia la estrecha relación de la sociedad industrial y sus transformaciones con la génesis de la Pedagogía Social) que los orígenes de ésta están asociados a la necesidad de intervenir socio-educativamente en una sociedad en crisis como consecuencia de las profundas alteraciones producidas por la industrialización.

Esta situación que afecta de modo peculiar a la Alemania de finales del siglo XIX, sumergida en la crisis económico-industrial iniciada en 1874 y prolongada más de veinte años, contribuirá a que sea en este país donde la Pedagogía Social adquiera no sólo su primera conceptualización, sino también sus mejores y más intensivas actuaciones.

Marburger señala que "la crisis político-social que afecta a Alemania en el último tercio del siglo reavivará la discusión pedagógica. Se busca en la educación un medio de solución a los problemas de la sociedad y emerge, al fin del siglo XIX, una nueva Pedagogía que estableció el ideal 
de la comunidad frente a la excesiva acentuación de la individualidad en la educación anterior, y fue designada como Pedagogía Social" (Marburger, 1979 en Arroyo, 1985, p.207).

En el relato secuencial del desarrollo histórico de la Pedagogía Social es común, como hemos indicado, atribuir el primer empleo del término "Pedagogía Social" a Adolph Diesterwerg. Así lo mencionan, por ejemplo, Hehlmann (1967), Groothoff-Stallmann (1971), Böttcher (1975), Böhm (1982). Recientemente se ha apuntado que otro autor K. Mager habría utilizado ya unos años antes, hacia 1844, este término de "Pedagogía Social" (Pankoke, 1981, p.8).

Diesterweg, en sus Escritos sobre Pedagogía Social incluidos en su obra "Guía orientadora para la formación del maestro alemán" alude a problemas de alcoholismo, a asociaciones femeninas con finalidad educativa, educación post-escolar o de los jóvenes sin escuela, instituciones de educación para pobres y huérfanos, escuelas para los más pequeños, para las clases trabajadoras. El término Pedagogía Social en este autor sirve para englobar contenidos y áreas de acción educativo-sociales sin que sea usado como resultado de una elaboración teóricosistemática.

No obstante, como señala Küchenhoff "para él (Diesterweg) como para muchos de sus contemporáneos interesados por la pedagogía, este término resumiría sus esperanzas de una pedagogía renovada" (1983, p.34).

\section{LA PEDAGOGÍA SOCIAL COMO DISCIPLINA CIENTÍFICA: FASES DE SU DESARROLLO}

Dentro de la evolución seguida por esta ciencia, podemos distinguir cuatro etapas, que no constituyen fases totalmente aisladas sino que suponen pasos en su desarrollo.

Una primera etapa se inicia con Paul Natorp (1854-1924). El profesor Romero Marín considera que en Natorp "la Pedagogía Social nace como una reacción contra el extremado individualismo pedagógico, representado en la antigüedad por los estoicos, en el Renacimiento por los Humanistas, en el siglo XVIII por Rousseau y en el XIX por el liberalismo individualista" (1948, p.221).

En esa perspectiva hay que situar la obra de este autor que publica en 1898, su obra fundamental "Sozialpädagogik", con el subtítulo "Teoría de la educación de la voluntad sobre la base de la comunidad". (Natorp, p.1915), obteniendo con ella el calificativo de fundador de la Pedagogía Social.

Utiliza "Pedagogía" y "Pedagogía Social" como términos equivalentes, de tal manera que la Pedagogía Social no constituye "una parte separable de la teoría de la educación, colocada tal vez al lado de la individual, sino la expresión concreta de la Pedagogía en general" $(1915,106)$. Dentro de su concepción la Pedagogía es una ciencia y una práctica educativa para la comunidad. Natorp dice textualmente: "Las condiciones sociales de la cultura y las condiciones culturales de la vida social son el tema de esta ciencia" (Natorp, 1915 en Radl, 1984, p.21). Señala el profesor José Ortega que "este objetivo encierra una finalidad práctica, de suyo infinita, que es la ilustración humana" (1999, p.19).

La fórmula sintética de su pensamiento podría resumirse, como señala Röhrs, en “Educación en la comunidad, por la comunidad y para la comunidad" (1973, p.363). 
Según Natorp la Pedagogía debe tomar en cuenta la totalidad del hombre y por lo mismo la totalidad de la cultura. La formación humana se lleva a cabo mediante un proceso que consiste en la asimilación de los valores culturales dados en la comunidad de vida.

Natorp (1915) mantiene una posición social radical respecto al hombre: de sus obras podemos entresacar la esencia de su idea, confrontando al hombre en sus aspectos individual y social. Expresiones suyas son: "Es un error eterno creer que se es individuo; a cada uno de los latidos de nuestra vida individual hace eco, física y psíquicamente la vida de la comunidad"; "La elevación del género humano entero a la altura de la naturaleza humana; la educación del pueblo, es decir, de todos los trabajadores por el trabajo y la cooperación hasta el más alto grado de cultura científica, moral y estética, lo es en la comunidad, por la comunidad y en cuanto comunidad"; "tratándose de determinar el fin de la educación el individuo carece de valor, es un simple material. El individuo no acertaría a ser el fin de la educación"; "el fin de la educación no puede ser otro que la socialización y, por ello, la moralización de la vida toda de un pueblo"; "el medio capital de la formación de la voluntad es la organización de la comunidad"; "la última ley es por necesidad la misma para el individuo y la comunidad"

La Pedagogía Social no es en Natorp, pues, una parte de la Pedagogía General como sostendrán otros autores de su tiempo (como Wilman, Beck y Edelheim) sino la Pedagogía en sí misma.

La segunda fase se inicia con Hermann Nohl y su discípula Gertrud Baümer que contribuyeron al nacimiento del "movimiento pedagógico social" de los años veinte y a la consolidación teórico-práctica de la Pedagogía Social; "retomaron los elementos concretos del proyecto pedagógico que se desarrolla en el campo educativo extraescolar incorporándolos en una teoría de la Pedagogía Social, según la cual no se trata de una disciplina pedagógica parcial, en el sentido de que se ocupe de un aspecto o de un principio general de la educación, sino de una disciplina científica de la educación, es decir, de una teoría que corresponde a un ámbito educativo delimitado y definido en su peculiaridad" (Küchenhoff, 1983, p.35).

Como señala el profesor Arroyo (1985, p.208) “corresponde a Nohl y a su discípula Baümer, no sólo el mérito de haber consolidado la articulación teórica de la Pedagogía Social, sino, sobre todo, el de haberla proyectado decididamente hacia la praxis. En esta época se sientan las bases de un gran número de instituciones que han perdurado posteriormente". En esta época fue dictada en Alemania la Ley Nacional de Protección a la juventud (1922); en ella aparece, por vez primera, el derecho jurídico del niño a la educación, así como el asentamiento de las bases jurídicas del objeto de la Pedagogía Social.

Nohl concibe la Pedagogía Social como una ciencia teórico-práctica con una serie de características, entre las que cabe citar:

- Afirmación de la realidad concreta como punto de partida de la teoría de la Pedagogía Social.

- La integración educativa de esfuerzos e iniciativas diversas que convergen en la ayuda a la juventud.

- El genuino objetivo de perseguir el bienestar del sujeto. La ayuda socio-pedagógica se reduce al ámbito del niño y del joven.

- La necesidad de modificar las condiciones ambientales para asegurar la eficacia de la acción pedagógico-social (Marburger, 1979). 
Baümer contribuye a la delimitación topológica de la misma, al considerar en el volumen V titulado: Pedagogía Social, incluido en el Manual de Pedagogía (editado por Nohl y Pallat, 1929) como un "sector de la Pedagogía: todo lo que es educación, pero no escuela ni familia" $(1929$, p.3).

La Pedagogía Social queda configurada como teoría y praxis del conjunto de actividades educativas fuera de la escuela, convirtiéndola en nuevo sistema, con nuevos entes e instituciones responsables, asignándole, de modo normal y no excepcional, determinadas funciones dentro del objetivo global de la formación de los jóvenes a cargo de la familia, la sociedad y del Estado. Tal concepción representa un paso de gran importancia para la construcción y consolidación de esta ciencia.

Las décadas de los años cincuenta y sesenta van a suponer un gran avance en el desarrollo de la Pedagogía Social, con lo que se entra en una tercera fase de su desarrollo.

Tras la Segunda Guerra Mundial, las necesidades surgidas en el contexto de la reconstrucción socio-económica, impulsan distintas iniciativas relacionadas fundamentalmente con la praxis pedagógico-social. Se abre una nueva fase en la Pedagogía Social orientada hacia la satisfacción de unas necesidades educativas agudas, en la que la praxis pedagógico-social alimenta la discusión teórica. Surgió así una "Pedagogía de urgencia" que iba llenando de tareas puntuales ese marco conceptual.

Se incide con claridad en el enfoque preventivo y en la necesidad de profundizar en el conocimiento de los factores sociales para lograr la integración social de las personas con problemas.

Como señala el profesor J.M. Quintana "han sido sobre todo autores posteriores a 1945 quienes han hecho de la Pedagogía Social la disciplina que proporciona la sistematización y el análisis del amplio campo del "Trabajo Social"; entre ellos destacan, K. Mollenhauer, H. Giexecke, W. Hornstein y Thiersch, quienes a partir de 1968 elaboran una Pedagogía Social crítica que se propone una revisión de la sociedad y de la educación, viendo cómo puede esta última ayudar a resolver los conflictos planteados en sus ámbitos comunes, y que tiene un carácter pragmático dentro del conjunto de las Ciencias Sociales" (1984, p.14).

Se puede afirmar que ésta es una etapa en la que proliferan los esfuerzos de sistematización y clarificación conceptual. Podemos hacer resaltar aquí especialmente, aparte de los ya señalados, a los autores Rünger (1964), Furck (1966), Pfaffenberger (1968), Iben (1969), Röhrs (1968). Este último publica en 1968 la obra colectiva "Pedagogía Social y su teoría", en la que puede verse una selección de los trabajos más importantes. También merece ser destacada la obra colectiva editada por K. Mollenhauer dos años antes (1966).

Mollenhauer amplia críticamente las ideas de Nohl y Baümer hacia una Teoría de la Pedagogía Social, destacando los factores económicos, políticos y sociales para su análisis, y viendo cada vez más la problemática juvenil como resultado de la situación educativa del hombre, y no como exigencia de una cualidad negativa de la persona a la que había que reeducar para la sociedad, ni por una incapacidad de la familia o de las personas.

Mollenhauer define la Pedagogía Social de la siguiente manera: "La tarea socio-pedagógica consiste así en todos los casos en la satisfacción de una necesidad educativa aguda, la cual está dada por la estructura de la sociedad moderna en comparación con la sociedad antigua. Tal 
necesidad educativa no se le puede atribuir sin más a una deficiencia de la sociedad moderna, sino a la forma de ser distinta de esta sociedad" (1959, p.124).

K. Mollenhauer es uno de los autores más destacados de la aportación en el campo de la Pedagogía Social de la teoría central sobre emancipación crítica.

En la Pedagogía Social como teoría crítica se parte del principio de que las formas individuales de comportamientos disociales y las estructuras sociales, de una sociedad determinada, tienen entre sí una dependencia funcional, de ahí que la Pedagogía Social como concepto social crítico, analiza en un primer paso (socialmente) las estructuras y en un segundo paso intenta cambiarlas de una manera pedagógicamente responsable para evitar o minimizar las causas de disociabilidad (Rald Philip, 1984). El fin de la Pedagogía Social crítica es "la transformación de la sociedad actual, en el sentido de llevar a la práctica las ideas que están determinadas en las Constituciones de las sociedades democrático-burguesas de igualdad, bienestar y libertad para todos" (Giesecke, p.1973).

La meta de la Pedagogía Social crítica es llevar a cabo una educación emancipativa, en un proceso dinámico, entendiendo al sujeto como un individuo con sus problemas, deseos, ideas y experiencias biográficas y no como un objeto de intenciones unilaterales por parte del pedagogo.

La teoría de la Pedagogía Social crítica tiene como objeto de estudio la solución de los problemas y tareas educativas que aparecieron en las sociedades modernas a raíz de la industrialización, pero como dichos problemas y conflictos también afectaron, cada vez más, a los campos tradicionales de la educación como la familia, escuela y profesión, la Pedagogía Social incluye también los procesos pedagógicos en estas áreas, y representa una teoría de las instituciones socio-pedagógicas, ya que son un aspecto bajo el cual se puede analizar y criticar a las instituciones educativas tradicionales (Mollenhauer, 1974).

A partir de los años setenta, la Pedagogía Social entra en una etapa de madurez, y que se prolonga hasta la actualidad configurándose una cuarta fase del desarrollo de la Pedagogía Social, cuyas características más significativas son las siguientes:

- Consolidación de la Pedagogía Social en el curriculum académico de las grandes Universidades europeas como disciplina principal pedagógica.

- Potenciación de la investigación en el campo de la Pedagogía Social.

- Ampliación del objeto de estudio. La Pedagogía Social va dirigida a cualquier persona, grupo, comunidad en "situación de necesidad" y a las distintas situaciones existenciales" y no solamente a la infancia y juventud en el ámbito extraescolar.

- Potenciación profesional de la Pedagogía Social. Apertura de varios campos profesionales para los pedagogos y educadores sociales.

- Consolidación y desarrollo de la denominada educación preventiva.

- Impulso de la actividad pedagógico-social encaminada a la reinserción social de sujetos inadaptados, marginados o conflictivos.

- Iniciación y establecimiento de la Pedagogía Social en el curriculum académico de las Universidades latinoamericanas (Brasil, Chile, Colombia, Ecuador, México, Argentina, ...)

En el desarrollo y consolidación de esta cuarta fase queremos subrayar también la organización y celebración de Jornadas, Encuentros, Seminarios y Congresos de Pedagogía Social (en septiembre de 2016 se celebra en Girona el XXIX Seminario Interuniversitario cuya temática es: Pedagogía Social, juventud y transformaciones sociales). 
Asimismo, la contribución de la Revista Interuniversitaria de Pedagogía Social, esta publicación nace en 1986 y se constituye como un medio idóneo de comunicación, confrontación e investigación, dedicada exclusivamente a este campo de trabajo. En su último número $(27,2016)$ es un monográfico dedicado a "La Pedagogía Social en el mundo".

Otro hecho destacable supone la constitución de la Sección Científica dentro de la Sociedad Española de Pedagogía (1985). En el año 2000 se constituyó la Sociedad Científica de Pedagogía Social y en el 2004 pasó a denominarse Sociedad Iberoamericana de Pedagogía Social a la que se incorporaron desde sus inicios muchos profesores universitarios y profesionales de esta área y que proporciona un marco de debate y de estudio que ayuda a su desarrollo científico y profesional.

\section{CONCEPTO DE PEDAGOGÍA SOCIAL}

\subsection{Diversas concepciones de la Pedagogía Social}

Es necesario reconocer que en la Pedagogía Social confluyen distintas concepciones relativas tanto a su teorización como a sus específicos campos de aplicación. Como señala el prof. Quintana, "la Pedagogía Social ha sido entendida y definida de diversas maneras, según los distintos países, autores y épocas. Y aún hoy día no existe una sola concepción de esta disciplina pedagógica" (1989, p.7). A este respecto, también nos apunta en su tratado de Pedagogía Social cinco concepciones de dicha disciplina (1984, p.18-25); de las que destacamos las tres principales:

\section{A. La Pedagogía Social como doctrina de la formación social del individuo}

En esta concepción, partiendo del reconocimiento de la condición social del individuo, la Pedagogía Social persigue la educación social de éste, propiciando el cultivo de las tendencias sociales inherentes a su persona, facilitando de esta manera su integración en la sociedad y su madurez social en orden al bien común.

Representa el modo más clásico de entender la Pedagogía Social, que queda concebida como una rama especial en el seno de la Pedagogía General. Ruiz Amado afirma que "la Pedagogía Social es la que procura educar al hombre, como naturalmente ordenado a vivir en sociedad. Supone, por ende, esta verdad: que el hombre es un ser social, y que sólo en sociedad puede obtener sus más elevados fines; por lo cual no basta que alcance su perfección como individuo, sino que esta perfección individual se ordene al perfeccionamiento de la sociedad" (1929, p.5).

\section{B. La Pedagogía Social como teoría de la acción educadora de la sociedad}

En esta teoría se atribuye a la sociedad el papel activo de educar a los miembros que la integran y se reconoce e impulsa por ello a los elementos y medios con posibilidad de formar, que existen en ella. La Pedagogía Social, en este sentido, impulsa dichos elementos y medios para que actúen de forma eficaz en orden a constituirse en educadores de los individuos y proporciona objetivos adecuados para ello.

En último extremo, persigue que la sociedad entera se constituya en una entidad educadora. "La sociedad desde este punto de vista desempeña un importante papel en la función educativa, a nivel del conjunto de las facetas de la persona. La ya clásica definición del hombre como ser social, conlleva un intercambio continuo de aprendizajes, entre los distintos componentes de la comunidad y el individuo. Este intercambio que se produce de forma primaria 
debe adquirir una nueva dimensión, al entronizar, en el contexto comunitario el papel de educador para el conjunto de la sociedad. Esta idea supone "fomentar una sociedad de aprendizaje, una sociedad culta y difusora de cultura y una sociedad que aprende a ser y a evolucionar", (Dave, 1979, p.54). Como vemos, esta idea es un factor de cambio en la sociedad, que pasa a ser un componente indispensable para la educación. $Y$ es que en este papel la sociedad misma, para cumplirlo de forma auténtica, debe tender a su propia perfección y desarrollo.

La concienciación de todos los entes sociales en su papel educador, potencia y motiva el desarrollo social" (Limón, 1988, p.138).

Esta concepción de la Pedagogía Social como una pedagogía de la acción educativa de la sociedad y de los medios de comunicación social impera en Italia, principalmente en autores como Agazzi, Mencarelli, Volpi, Volpicellicelli. En España participan de ésta (aunque no totalmente) los profesores José Ortega, Escarbajal de Haro, Martí March, Antoni Colom y José Antonio Caride. Este último dice refiriéndose a esta concepción: creemos que en su estimación cabe encontrar el origen del modelo de intervención socio-educativa y animación socio-cultural que diseña y promueve la constitución de la sociedad pedagógica" (1985, p.120).

Es necesario para la mejor comprensión de esta teoría exponer, aunque sea muy brevemente, una serie de citas de los autores italianos que consideramos esclarecerán la verdadera dimensión de esta concepción.

Así para Volpi la Pedagogía Social "es la teoría y la praxis de una sociedad educadora y su justificación funcional reside en el hecho de que cada sociedad "valiéndose por sí misma como orden educador debe activar correctamente las estructuras y los subsistemas que la componen" (1982, p.58).

Por su parte, Agazzi señala que "no se trataría de educar socialmente al individuo, sino de hacer posible que la sociedad misma se convierta en educadora a través de ciertos cuerpos intermedios (familia, sindicatos, Iglesia, medios de comunicación...) que son los que verdaderamente deberían merecer la atención de la Pedagogía Social". (1974, p.27-28).

Para Mencarelli "la Pedagogía Social tiene un objetivo especifico, desarrollar la dimensión educativa de las estructuras y subestructuras sociales" (1975, p.6).

Es destacable la afirmación que hace Volpi (1982) al señalar que la Pedagogía Social debe situarse en una posición intermedia entre teoría y praxis educativa y desenvolverse en una continua hipótesis de Educación Permanente.

El estudio de esta concepción en nuestro país fue llevado a cabo por el profesor Quintana que en el número cuatro de la Revista de Pedagogía Social (1989, p.7-27) hace una exposición de la Pedagogía Social en Italia y por Andrés Escarbajal, en la misma publicación, que en su artículo sobre la concepción "societa educante" estudia las ideas de los autores arriba mencionados, y señala que "en lo que parece que están bastante de acuerdo todos (refiriéndose a los autores italianos) es en la extensión del término "societa educante" como filosofía sustentadora de la Pedagogía Social". (1989, p.186). También desarrolla este concepto en su libro "Educación extraescolar y desarrollo comunitario" (Escarbajal, 1991).

Para Mario Mencarelli (1975, p.31), este término (Societá Educante) debe ser entendido como la organización y puesta en práctica de todas los servicios educativos, escolares y extraescolares, en función de una continuidad entre la escuela y la sociedad. Por tanto, esta 
perspectiva va encaminada a vehiculizar un sistema coordinado de servicios educativos para conseguir una efectiva relación entre las instancias educativas, y evitar que actúen como compartimentos estancos, llegar a una "Societá Educante" en el sentido dado por Bertolini (1978, p.233-234): "Sociedad que permite y estimula la integración y coordinación de los tres momentos educativos fundamentales, hasta ahora, esquizofrénicamente separados $y$, a veces, enfrentados como contradictorios: familia, escuela y ambiente extraescolar".

C. La Pedagogía Social como doctrina de la beneficencia Pro infancia y juventud. Posteriormente se formula como doctrina de la atención a problemas humano-sociales que pueden ser tratados desde instancias educativas.

Tiene sus orígenes (como ya hemos señalado), asociados a la sociedad industrial y a las profundas alteraciones que se producen ante los fenómenos de masificación urbana, proletarización del campesinado, relajación de vínculos familiares, desigualdades sociales, deficiente escolarización, pobreza, etc. (Mollenhauer, 1959), y también está contextualizada en las consecuencias de las Guerras Mundiales.

Sus autores más representativos son: Nohl, Baumer, Steiger, Rossner, Mollenhauer.

Esta teoría ha tenido su cuna y su máximo desarrollo en Alemania, constituyendo una concepción vigente y bien afianzada en la teoría y en la práctica. En España, queremos subrayar la aportación de los profesores Millán Arroyo, José Ortega Esteban, Quintana Cabanas y Antoni Petrus que, a través de sus estancias en las Universidades alemanas y a través de sus escritos, nos han permitido conocer más de cerca esta concepción de la Pedagogía Social, que ha beneficiado y beneficia no sólo a la Universidad española, sino a toda la sociedad.

Esta concepción de la Pedagogía Social, que en un principio abarca a la infancia y a la juventud necesitada, posteriormente se extiende a todo tipo de población o de comunidad social que se encuentran en situación de "necesidad" y "riesgo" y que reclaman una especial ayuda educativa.

La Pedagogía Social abarca todas aquellas tareas educativas que se suscitan en los lugares conflictivos de la sociedad industrial y que en ésta han venido a hacerse necesarias como medios auxiliares particulares. En este sentido, existe la Pedagogía (Social) sólo desde que se han sometido los sucesos sociales a una crítica pedagógica y se hizo evidente que las vías educativas tradicionales resultaban ya insuficientes para asegurar el proceso de desarrollo personal.

Mollenhauer (1968, p.288-314) dice que la Pedagogía Social como término referente a un determinado complejo de tareas y de instituciones, es algo distinto de lo mencionado en el concepto de socialización; este concepto determina únicamente una más entre las diversas funciones educativas, indiferentemente de si se dan en la familia, en la escuela, en el lugar de trabajo o en una institución pedagógico-social. El concepto de Pedagogía Social, por el contrario, viene ligado a instituciones educativas que tienen un tipo determinado de tareas.

Quintana, por su parte, al analizar esta teoría, interpreta que "entiende la Pedagogía Social como la ayuda que la Pedagogía debe aportar a la sociedad para lograr la solución de deficiencias sociales que constituyen problemas urgentes en relación con el desarrollo y perfeccionamiento de los individuos" (1984b, p.121).

Según este concepto, la Pedagogía Social debería ocuparse de cuestiones como las siguientes: la asistencia material y moral a la infancia y juventud abandonadas, la lucha contra el 
analfabetismo, la marginación social, la prevención y corrección de la delincuencia juvenil, los tribunales tutelares de menores, las guarderías infantiles, el trabajo juvenil, la salvaguardia de los derechos del niño, las colonias de vacaciones, la orientación profesional y las actividades del tiempo libre de niños y jóvenes. También abarcaría la educación compensatoria, la educación de adultos, la de la tercera edad, la promoción comunitaria, socio-educativa, la resocialización y rehabilitación de sujetos marginados, abandonados o asociales.

Para el profesor Caride presenta "una visión reduccionista y parcializada en las posibilidades del trabajo socio-educativo, con el riesgo implícito de asumir planteamientos excesivamente proteccionistas, paternalistas o redencionistas" (1985, p.120).

Consideramos que la Pedagogía Social no puede quedar reducida a una Pedagogía de la necesidad o la marginación (aunque este aspecto sea de mucha, o mejor dicho de vital importancia), sino que debe abarcar a todo el contexto social. Por tanto, la aplicación de la Pedagogía Social a esos sectores marginados o necesitados debe ser una parte especializada de ella, pero nunca la totalidad.

El profesor Romero Marín, señalaba en el año 1948 que "todavía no hay unanimidad entre los pedagogos en el alcance y significación de la Pedagogía Social" (1948, p.223). Podemos decir sesenta y ocho años después que la identidad científica de la Pedagogía Social no la configura una teoría determinada sino el conjunto de las teorías existentes. Ya que se hace necesario reconocer que en la Pedagogía Social confluyen distintas concepciones relativas tanto a su teorización como a sus específicos campos de aplicación.

\subsection{El pensamiento sobre la Pedagogía Social del Profesorado del Departamento de Teoría e Historia de la Educación de la Universidad Complutense de Madrid}

Veamos ahora brevemente como están representadas las precedentes teorías por algunos profesores del área de Pedagogía Social del Departamento de Teoría e Historia de la Educación.

Para el profesor Arroyo (1985, p.205) la Pedagogía Social "se ocupará de la teoría y praxis del perfeccionamiento del hombre como ser social, es decir, en todo aquello que se relaciona con su personalidad o conductas sociales, actitudes, hábitos, comportamientos, que promueven positivamente los valores sociales del individuo y de la comunidad, entendidos como valores sociales educativos". También tendrá como objeto la ayuda de índole educativa prestada a sujetos en situación de necesidad, especial riesgo, problemática, conflictiva, de desvalimiento, etc. Una ayuda de la que se responsabiliza toda la sociedad en cuanto comunidad solidaria del bien común, y obligada a velar por la existencia de condiciones mínimas que aseguren a todos sus miembros el respeto efectivo de sus derechos y libertades, y la superación de las dificultades que han de afrontar para una autorrealización de su persona.

Cuatro grandes objetivos asigna el Profesor Millán a la educación social:

1. Educación para una actitud social frente a los conciudadanos (ordenada, ante todo, al desarrollo y ejercicio de la actitud social básica de justicia y amor, y a la educación para la responsabilidad en la participación conjunta de ideas y acciones al servicio de la sociedad).

2. Instrucción sobre los elementos constitutivos y reguladores de la sociedad y sus funciones, así como las eventuales situaciones de riesgo individual y social, y sus principios de solución. 
3. Procurar que cada uno encuentre su puesto adecuado en la sociedad y lo desempeñe satisfactoriamente.

4. Ayudar a los hombres que se encuentran en situaciones de riesgo y necesidad.

El profesor Alvaro Buj expuso en el VII Seminario Interuniversitario de Teoría de la Educación (Valencia, 1988) su concepción de la Pedagogía Social y así dice: "yo entiendo por Pedagogía Social, la teoría y técnica de la formación social de los individuos, siendo una ciencia normativa que se ocupa, especialmente, de la intervención pedagógica sobre individuos y grupos sociales que se encuentran en situaciones problemáticas o carenciales y necesitan integrarse socialmente" (1988, p.1).

Atribuye, pues, una doble tarea a la Pedagogía Social:

- De una parte, la formación social generalizable a todos los individuos,

- y de otra, la acción correctiva, terapéutica y de reinserción social.

"La Pedagogía Social desarrolla modelos teóricos que explican en qué consiste la educación social, actúa en la formación del individuo aplicando normas basadas en la concepción del hombre como ser social, es decir, necesariamente integrado en la sociedad y, en su quehacer operativo utiliza determinadas técnicas; todo lo cual, se da con independencia de que su ámbito lo formen individuos adaptados a la dinámica social, por gozar de un proceso socializador normal, o bien actúe fuera de los contextos objeto de la educación sistemática y formal". (1988, p.1).

Para este profesor, que por haber ejercido la función inspectora conocía extensa y profundamente la realidad escolar, la Pedagogía Social tiene que entrar de lleno no sólo en el ámbito extraescolar, no formal, sino en el ámbito escolar si realmente se pretende llevar a cabo una sólida formación social dentro de una educación integral. Actualmente, hay Educadores Sociales trabajando en el ámbito escolar en colaboración con los Servicios Sociales.

El profesor J.V. Merino dice que "el objeto fundamental de la Pedagogía Social es ofrecer la ayuda necesaria y suficiente para que el hombre, durante todas las etapas de su vida, desarrolle correctamente y con éxito su propio proceso de socialización. En suma, que la función primordial de la Pedagogía Social es investigar, diseñar y ejecutar la educación social adecuada a dicho propósito". (1986, p.113).

Según él, la Pedagogía Social debe dirigirse a un doble frente de actuación, con el fin de ofrecer a los individuos y a los grupos humanos la ayuda más eficaz en su proceso de socialización, de tal manera que éste no se convierta en simple acomodación pasiva a la sociedad, sino que sea un proceso autónomo, asimilador y creador, libre, responsable y constructor de una personalidad social madura e integrada. El primer frente debe ser conseguir una educación social posibilitadora de que el individuo sea el artífice principal de su socialización; el segundo, procurar, mediante el trabajo social, que la fuerza de la dinámica social con sus dificultades y problemas, no haga desviarse o fracasar el personal e intransferible proceso de socialización" (Merino, 1986, p.117).

El profesor López Herrerías (1989, p.27-28) considera la Pedagogía Social como programa de Diseñación Cultural:

“Entendemos la Pedagogía Social como: 
- El programa de mejora, promoción y prevención (reinserción de vivencias socioculturales en que se plasma) (ámbito objetivo, externo).

- La optimización educativa (de la dimensión humanizante/ antropogenizadora de lo social) (ámbito subjetivo, interno).

Entender la Pedagogía Social como un programa nos indica el paradigma comunicacional desde el que contemplamos la praxis de este conocimiento".

Yo concibo la Pedagogía Social como la teoría y práctica de la educación social, tanto de los individuos como de los grupos y en último término, del conjunto de la sociedad, a fin de lograr la plena integración de todos los elementos que la constituyen y el desarrollo de la misma, orientado al bien común y a la mejora de la calidad de vida, con especial dedicación y atención a aquellas personas y grupos en situaciones marginales o carenciales que necesitan integrarse socialmente.

El término educación social supone dotar a los individuos y a los distintos grupos sociales, de los conocimientos, instrumentos y medios que los capaciten para ser sujetos activos y protagonistas de dicha plena integración y desarrollo de la sociedad. Esto implica la necesidad de poner ante los ojos del educando el ideal de una sociedad mejor, insertando a éste en la sociedad real y al mismo tiempo, proporcionándole un proyecto de mejora y desarrollo de la misma.

En relación con la sociedad en general, la Pedagogía Social debe tender a modificar las estructuras sociales sustituyéndolas por otras que posibiliten dicha plena integración de todos sus miembros, y creando nuevos espacios educativos que faciliten la integración y la promoción social.

Ahora bien, no olvidemos que la Pedagogía Social tiene como principal misión la lucha no solo correctora sino preventiva contra la marginación y los estados carenciales. Y es en este aspecto donde toma pleno sentido y donde adquiere mayor relevancia.

Por el Real Decreto 1420/1991, de 30 de agosto, se establece el Título Universitario oficial de Diplomado en Educación Social (BOE 10 de octubre de 1991) y se señala que las enseñanzas conducentes a la obtención de este Título deberán orientarse "a la formación de un educador en los campos:

\section{Educación no formal}

2. Educación de adultos (incluidos los de la tercera edad)

3. Inserción social de las personas desadaptadas

4. Inserción social de personas minusválidas

5. La acción socio-educativa"

En el curso académico 2009-2010 comenzó la implantación del nuevo Título de Grado en Educación Social en algunas de las universidades españolas, entre las que se encuentra la Universidad Complutense de Madrid, como compromiso de adhesión al proceso de convergencia del Espacio Europeo de Educación Superior (EEES) (De-Juanas et al. , 2014 ). 


\subsection{En síntesis:}

Los objetivos de la Educación Social son:

1. Potenciar los recursos personales del ciudadano, sea cual fuere su situación social.

2. Potenciar y estimular el desarrollo y el uso de los recursos comunitarios.

3. Facilitar el acceso de los ciudadanos a estos recursos.

4. Posibilitar la relación personal entre los miembros de un grupo social.

5. Facilitar y posibilitar el crecimiento personal y comunitario del grupo social.

6. Insertar al ciudadano en su sociedad inmediata.

7. Facilitar la adquisición de pautas de convivencia social.

8. Ser un agente o factor de cambio social.

9. Adoptar estrategias de intervención a fin de afrontar los problemas de desequilibrio social.

10. Desarrollar un sentido crítico frente a las diferentes situaciones sociales.

Las funciones genéricas del Educador Social son:

1. Funciones relacionadas con la reinserción social, la salud mental y social y la adaptación de la persona.

2. Funciones relacionadas con la producción, con el mundo del trabajo y con la formación profesional.

3. Funciones relacionadas con la escuela y otras instituciones educativas.

4. Funciones relacionadas con la extensión cultural y la educación permanente.

5. Funciones relacionadas con la vida cotidiana.

El Educador Social interviene en:

- Tres tipo de acción social:

- primaria, secundaria y terciaria

- Con población normalizada, con población en riesgo y con población inadaptada y marginada

- Equipamientos, instituciones y centros, que a su vez puede ser:

- abiertos, semiabiertos y cerrados

- Centros, medio abierto o instituciones y con programas de intervención que pueden ser:

- Públicos, privados y concertados 
Los ámbitos sobre los que ejerce su función el educador social son:

- Sobre un individuo concreto

- Sobre un grupo determinado

- En una realidad familiar

- En el espacio de lo escolar

- Un barrio o comunidad

- Dentro de una estructura jurídica o de Servicios Sociales

- En un espacio laboral o profesional

- En función de lo cultural

- En un sector de intervención especializada

- Dentro de la sociedad en general

Una formación universitaria en Educación Social debe asegurar, mínimamente las siguientes áreas:

$$
\text { SABER - SABER SER - SABER HACER }
$$

- Una formación humana que garantice la madurez personal, el saber y el saber ser del Educador Social.

- Una formación pedagógica que asegure el saber y garantice una racionalidad educativa al saber hacer a través de las distintas intervenciones.

- Una formación técnica que garantice el saber hacer y complemente la formación pedagógica.

- Una formación socio-comunitaria como garantía de una correcta ubicación del educador en el entorno social en el que corresponda intervenir.

- Una formación permanente a lo largo de su actividad profesional.

\section{BIBLIOGRAFÍA}

1. AGAZZI, A. La pedagogia sociale come teoria e prassi della societá educante. Pedagogia e Vita, serie 36,1, p. 5-9, 1974.

2. ARROYO SIMÓN, M. ¿Qué es la Pedagogía Social? Bordón, 257, p.201-215., 1995.

3. ARROYO SIMÓN, M. La especialidad de "pedagogía social" en la universidad alemana R.F. Plan de Estudios. Revista de Pedagogía Social, 3, p.123-136, 1998.

4. BAÜMER, G. Die historischen und soziologischen Voraussetzungen der Sozialpädagogik und die Entwicklung ihrer Theorie. En: NOHL, PALLAT (Eds.). Hanbuch derPädagogik, vol. V, Langesolza: Beltz, 1929. p.3-26. 
5. BERTOLINI, P. L'operatore pedagógico. Problemi e prospettive. Bologna: Cappelli, 1984.

6. BÖHM, W. Wörterbuch der Pädagogik (12.a ed.). Stuttgart: Kröner, 1982.

7. BÖTTCHER, H. Socialpädagogik in Überblick. Friegurg: Herder, 1975.

8. BUJ GIMENO, A. Funciones de la Pedagogía social en la formación de los escolares. VII Seminario Interuniversitario de teoría de la educación. Valencia: Departamento de Teoría de la Educación. Documento poligrafiado, 1988.

9. CARIDE, J.A. Educación y Animación Sociocultural: la pedagogía social como modelo de intervención. En: QUINTANA, J.Mạ. Fundamentos de animación sociocultural, Madrid: Narcea, 1985. p. 94-127.

10. CARIDE, J.A. Hacia una configuración curricular de la pedagogía social en la universidad. ¿Qué contenido? Revista de Pedagogía Social, 3, p.101-108, 1988.

11. COLOM, A. La pedagogía social como modelo de intervención socio-educativa. Bordón, 247, p.165-180, 1983.

12. COLOM, A. Pedagogía Social y Política (Las A.A. de V.V. como modelo de educación social informal). Revista de Pedagogía Social, 3, p.49-70, 1988.

13. DAVE, R.H. et al. Fundamentos de la educación permanente. Madrid: Santillana / Instituto de la UNESCO para la Educación, 1979.

14. DE-JUANAS, A.; LIMÓN, Mạ R.; MELENDRO, M. Práctica Profesional y Formación del Educador Social en España. Interfaces Científicas- Educacao- Aracaju- V.3 - N.1 - p. 89-102, 2014

15. DIESTERWEG, A. Wegweiser für Bildung der deutsche Lehrer, vol. 1, 4a ed. Essen, 1850.

16. ESCARBAJAL DE HARO, A. Educación extraescolar y desarrollo comunitario. Valencia: Nau Llibres, 1991.

17. ESCARBAJAL DE HARO, A. Una visión de la Pedagogía y la concepción de "Societá Educante" en Italia. Revista de Pedagogía Social, 4, p.181-198, 1989.

18. FURCK Die Aufgaben der Sozialpädagogik in der Gegenwart. En: MOLLENHAUER, K. (Ed.)., Zur Bestimmung von Sozialpädogogik un Sozialarbeit in der Gegenwart, Weinheim: Beltz, 1966. p.46-66.

19. GROOTHOFF, H.H.; STALLMANN, M. (Hrsg). Neues Pádagogisches Lexikon. Stuttgart/Berlín: Kreuz Verlag, 1971.

20. HEHLMANN, W. Wórterbuch der Pádagogik. (8aed). Stuttgart: Króner, 1967.

21. KÜCHENHOFF, W. Pedagogía social. En Diccionario de la Ciencia de la Educación, Madrid: Rioduero, p.34-38, 1983.

22. LIMÓN MENDIZÁBAL, R. Educación permanente y educación de adultos en España. Colección 'Tesis Doctorales. núm. 409/88. Madrid: Universidad Complutense, 1988.

23. LIMÓN MENDIZABAL, R. La Pedagogía Social como disciplina académica. Educadores, 162, p.233-245, 1992.

24. LÓPEZ HERRERÍAS, J.A. Objeto y método de la Pedagogía Social. Revista de Pedagogía Social, 4, p.27-46, 1989.

25. LUZURIAGA, L. Pedagogía social y política (5a ed.). Buenos Aires: Losada, 1968. 
26. MARBURGER, H. Entwicklung und Konzepte der Sozialpädagogik. München: Juventa, 1979.

27. MENCARELLI M. II diritto all' educazione como frontera della pedagogía sociale. La Scuola, Brescia, 1975.

28. MERINO, J.V. Educación social. En: Nueva Acta 2000. Educación y Comunicación, T. 4, Madrid: Rialp, 1982, p.103-110.

29. MERINO, J.V. Exigencias de integrar teoría y práctica en la formación del Pedagogo social. Presentación de una experiencia concreta. Educar, 9, p.111-134, ,1986.

30. MOLLENHAUER, K. Die Ursprünge der Sozialpädagogik in der industriellen Gesellschaft. Weinheim: Beltz, 1959.

31. MOLLENHAUER, K. et al. Zur Bestimmung von Sozialpädagogik und Socialrbaeit in der Gegenwart. Weinheim: Beltz, 1966.

32. MOLLENHAUER, K. Sozialpädagogik. En: GROOTHOFF, H. (Ed.). Pádagogik. Frankfurt: Fischer,1973.

33. NATORP, P. Pedagogía Social. Madrid: La Lectura, 1915.

34. NATORP, P. Sozialpädagogik. Theorie der Willenserziehung auf der Grundlage der Gemeinschaft. Stuttgart: F. Frommanns, 1898.

35. NEGRÍN, O. Pedagogía Social. Técnica de trabajo escolar. Unidad Didáctica-6.Madrid: UNED, 1977.

36. NOHL, H.; PALLAT, L. Handbuch der Pädagogik. Langesalza: Beltz, 1929.

37. ORTEGA ESTEBAN, J. (Coord.). Pedagogía Social Especializada. Pedagogía de menores en dificultad y en conflicto social. Barcelona: Ariel Educación, 1999.

38. ORTEGA ESTEBAN, J. Educación a lo largo de la vida o el espacio de la educación social. En: PANTOJA, L. (Ed.). Nuevos espacios de la educación social, Bilbao: Ediciones Mensajero, p.161-182, 1998.

39. ORTEGA ESTEBAN, J. La idea de ciudad educadora a través de la historia. En: TRILLA, J. (Coord.). La Ciudad Educadora, Barcelona: Ajuntement de Barcelona, p.92-102, 1990.

40. PANKOKE, E. Gesellschafflicher Wandel und Soziale Dienste. Vorausstzungen und Entwicklungsperspektiven. En: KERKHOFF, E. (Hrsg.). Handbuch Praxis der Sozialarbeit und Sozialpádagogik. Bd. 1. Grundlangen und berufsfeldorientierte Schwerpunkte, Dússeldorf: Pádagogischer Werlag Schwann, 1981, p. 3-30.

41. Pedagogía Social. Revista Interuniversitaria. Monográfico: La Pedagogía Social en el mundo. N.27, 2016.

42. PESTALOZZI, J.H. Grundlehren über Mensch, Staat. Erziehung (Hrsg. v. H. Barth). Stuttgart: Króner, 1956.

43. PETRUS, A. (Coord.). Pedagogía Social. Barcelona: Ariel Educación, 1997.

44. PFAFFEnBERGER, H. Das Theorie und Methodenproblem der sozialpädagogischen und sozialen Arbeit. En: RÖHRS, H. (Ed.). Die Sozialpädagogik und ihre Theorie. Sututtgart: Akademische Verlag-sgesellschaft, 1968.

45. QUINTANA, J.Mạ. La Pedagogía Social en Italia. Revista de Pedagogía Social, 4, p.7-27, 1989. 
46. QUINTANA, J.Mạ. Pedagogía Social. En Diccionario de Ciencias de la Educación "Sociología y Economía de la Educación", Madrid: Anaya, p. 120-122., 1984b.

47. QUINTANA, J.Ma. Pedagogía Social. Madrid: Dykinson, 1984.

48. RADL, R. Conceptos, teorías y desarrollo de la Pedagogía Social. Bordón, 251, p.17-43, 1984.

49. RÖHRS, H. A llgemeine Erziehungswissenschaft. Weinheim: Beltz, 1973.

50. RÖHRS, H. Die Sozialpädagogik und ihre Theorie. Frankfurt Main: Akademische Verlagsgesellschaft, 1968.

51. ROMERO MARÍN, A. Concepto, método, fuentes y programa de Pedagogía General y Pedagogía Racional. Memoria para la Cátedra de estas disciplinas en la Universidad de Madrid, 1948.

52. RUIZ AMADO, R. Educación social. Barcelona: Librería Religiosa, 1929.

53. RÜNGER, H. Einführung in die Sozialpädagogik. Witten: Luther Verlag, 1964.

54. VIVES, J.L. Del socorro de los pobres. Madrid: Edic. de La Lectura, 1931.

55. VOLPI, Cl. Tareas y funciones de la Pedagogía Social. Revista de Pedagogía Social, 1, p.29-38, 1986.

56. VOLPI, Cl.; MAZZATOSTA, T.Ma. Storia e educazione civica. Firenze: Le Monnier, 1982.

57. VOLPICELLI, L. Saggi di pedagogia sociale. Roma: Bulzoni, 1974.

\section{ANEXO}

Presentamos en este apartado y, a través de estas imágenes, algunas ideas tratadas en este artículo:

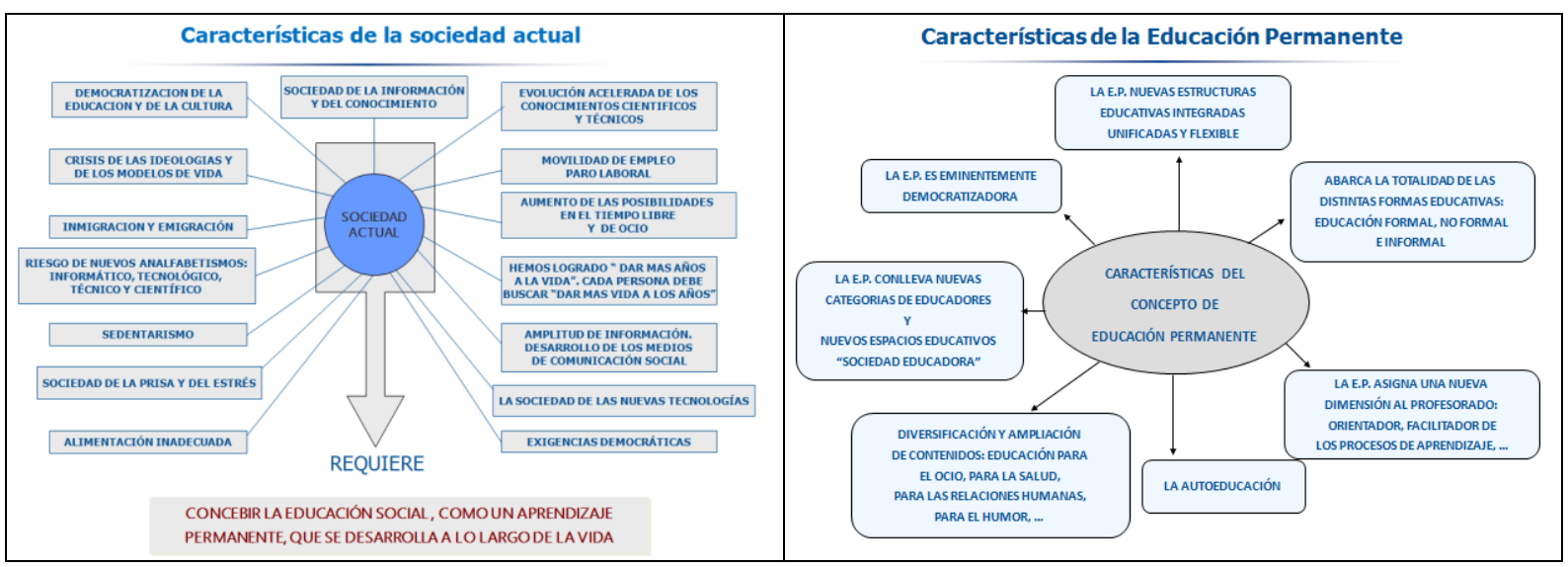




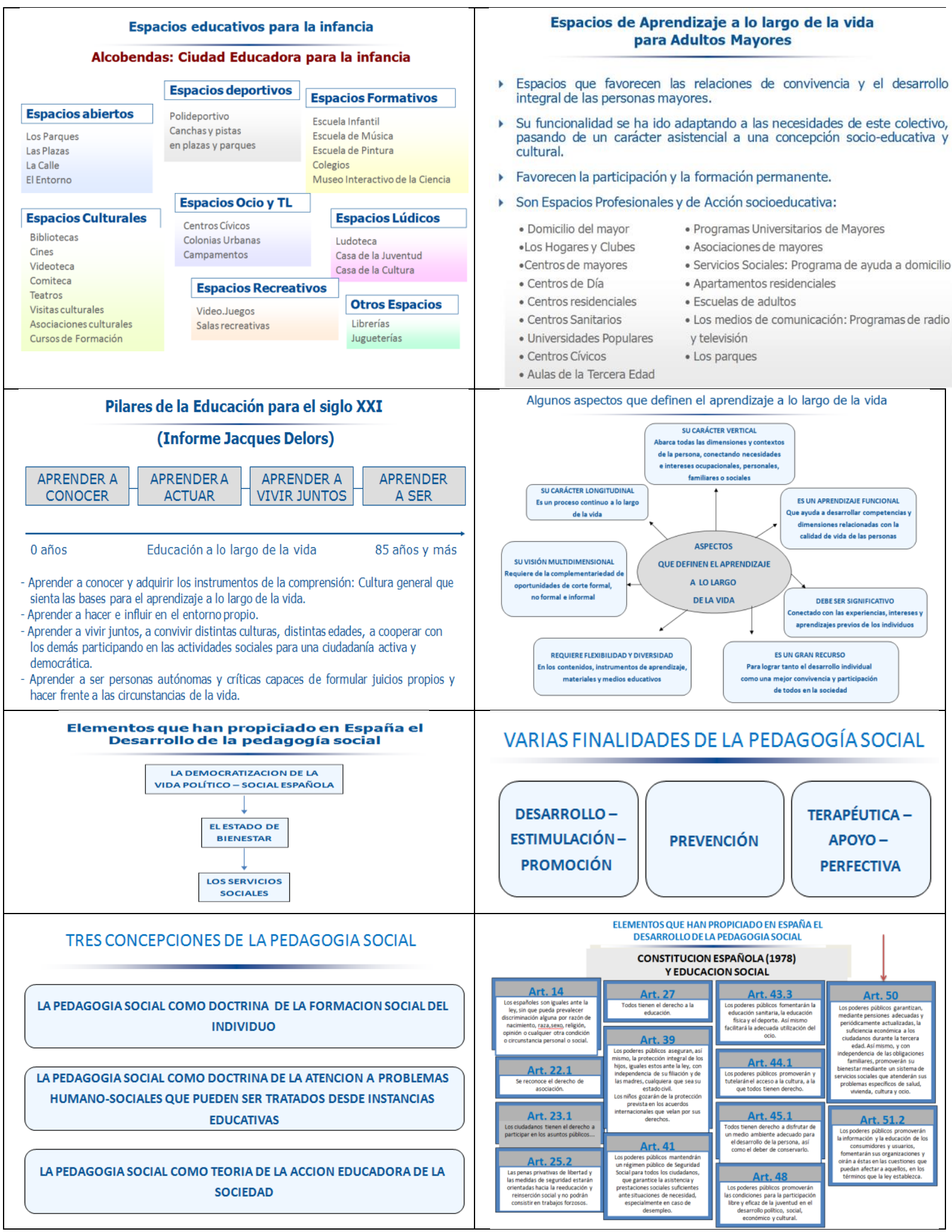

